\title{
Low Tidal Volume Ventilation: Trust but Verify
}

Despite affecting an estimated $4-7 \%$ of patients in the ICU and having a high mortality rate, there are currently a limited number of therapeutic options to treat patients with ARDS.1,2 ARMA, the landmark ARDSnet trial in 2000, established the concept of lungprotective ventilation, where subjects with ARDS receiving mechanical ventilation were randomly assigned to a set tidal volume $\left(\mathrm{V}_{\mathrm{T}}\right)$ of either 6 or $12 \mathrm{~mL} / \mathrm{kg}$ predicted body weight, calculated from measured height. ${ }^{3}$ This trial demonstrated a significant reduction in mortality in the low $\mathrm{V}_{\mathrm{T}}$ arm. As a consequence, it provided strong evidence for abandoning the conventional wisdom of setting ventilation to normalize $\mathrm{pH}$ and $\mathrm{P}_{\mathrm{CO}_{2}}$ in favor of the emerging view that protective low $\mathrm{V}_{\mathrm{T}}$ ventilation and permissive hypercapnia could avoid pulmonary mechanical stress and ventilator-induced lung injury (VILI). Although not explicitly stated in the original publication, the ARMA trial used heelto-crown height measured in supine subjects. ${ }^{4}$ Although clinical practice has shifted toward targeting lower $\mathrm{V}_{\mathrm{T}}$ levels estimated from height, height measurements have not been standardized; in the real world, height is often obtained from patients or family members, or visually estimated by staff. Subsequent observational trials have demonstrated that height is often overestimated to the detriment of some patients, especially in the case of short and obese females. ${ }^{5-7}$ The low frequency of heelto-crown height measurements in patients with ARDS is probably due to multiple factors, including time, perceived inaccuracy of height measurements in a critically ill supine patient, and a lack of appreciation that accurate height measurements can alter mortality.

The study by Jurecki et $\mathrm{al}^{8}$ explores the complexity of setting low $V_{T}$ for the purpose of lung-protective ventilation; the variation in estimated set $\mathrm{V}_{\mathrm{T}}$ depends on height estimates which may vary considerably depending on the source used to estimate height. The authors found that, for the study population, the mean height obtained from the

\footnotetext{
The authors have disclosed no conflicts of interest.

Correspondence: Maher Ghamloush MD, Division of Pulmonary, Critical Care, and Sleep Medicine, Department of Medicine, Tufts Medical Center, 800 Washington Street, Box 257, Boston, MA 02111. E-mail: mghamloush@tuftsmedicalcenter.org.
}

DOI: $10.4187 /$ respcare. 04530 electronic health record is similar to the mean predicted height calculated from ulnar length. However, for individuals, differences in height between the 2 sources can be large, leading to large differences in predicted body weight and resultant $\mathrm{V}_{\mathrm{T}}$ set in $\mathrm{mL} / \mathrm{kg}$. The authors did not obtain the accepted standard heel-to-crown height measurements

\section{See the Original Study on Page 1715}

that were obtained in ARMA; hence, a purist would argue that, in the absence of such measurements, it would be pure speculation which of the height estimations one should follow in setting $\mathrm{V}_{\mathrm{T}}$. However, the results are still of interest because they show a real difference between the 2 methods of estimating set $\mathrm{V}_{\mathrm{T}}$, with clear consequences for individual subjects. For example, a visual scan of the BlandAltman plots demonstrates that at least 6 of 27 males (22\%) and at least 6 of 24 females $(25 \%)$ had differences between charted and predicted average $\mathrm{V}_{\mathrm{T}}$ /predicted body weight $>1 \mathrm{~mL} / \mathrm{kg}$ when the authors assumed that all $\mathrm{V}_{\mathrm{T}}$ levels were set to $8 \mathrm{~mL} / \mathrm{kg}$. Although the difference in $\mathrm{mL} / \mathrm{kg}$ would probably appear smaller if $\mathrm{V}_{\mathrm{T}}$ were set at $6 \mathrm{~mL} / \mathrm{kg}$, such differences are still cause for concern. This concern is magnified by another study suggesting that even when limiting set $\mathrm{V}_{\mathrm{T}}$ to $6 \mathrm{~mL} / \mathrm{kg}$, such an approach may lead to tidal hyperinflation and potential injury of normally aerated lung in one third of subjects. ${ }^{9}$

The issues raised by Jurecki et $\mathrm{al}^{8}$ and other studies suggest that a one-size-fits-all method of setting $\mathrm{V}_{\mathrm{T}}$, although certainly benefiting the population overall, may be problematic for a subgroup of patients. Other strategies to further limit VILI include using esophageal balloon monitoring to limit transpulmonary pressures or further limiting lung volumes by using ultra low $\mathrm{V}_{\mathrm{T}}$ (ie, $4 \mathrm{~mL} / \mathrm{kg}$ or high frequency oscillatory ventilation) or extracorporeal membrane oxygenation. However, many of these interventions may not be cost-effective or are of uncertain benefit as of yet. A promising more tenable approach would tailor the set $\mathrm{V}_{\mathrm{T}}$ to the individual physiology of the patient and revolves around the concept of setting $\mathrm{V}_{\mathrm{T}}$ to the size of the functional or baby lung, which was defined as the normally aerated lung tissue in ARDS patients. ${ }^{10}$ This concept emerges from the realization that ARDS often affects the lungs quite heterogeneously and that setting $\mathrm{V}_{\mathrm{T}}$ to the size of the entire lung in the nondiseased state, as estimated 
from height, may lead to high inflation pressures and consequent volutrauma and barotrauma in the remaining nondiseased functional lung. This concept was demonstrated in a recent study by Amato et al, ${ }^{11}$ where the authors performed a meta-analysis of 9 randomized controlled trials targeting either $\mathrm{V}_{\mathrm{T}}$ or PEEP and demonstrated that the driving pressure (defined as the difference between plateau pressure and PEEP) is inversely proportional to survival. When driving pressure was included in the models as a co-variate, it was the only factor that provided independent predictive information to any survival model. From a physiologic perspective, driving pressure reflects transpulmonary pressures in most situations; hence, limiting driving pressure may theoretically reduce transpulmonary pressure and consequently limit VILI. However, the question remains whether limiting driving pressure can lower mortality or whether driving pressure is only a marker of the degree of injury.

In view of these issues, how should we be practicing mechanical ventilation in our intensive care units today? Should we abandon the concept of low $\mathrm{V}_{\mathrm{T}}$ ventilation in favor of variables more predictive of transpulmonary pressures, such as driving pressure? The answer today remains no. Driving pressure also has its limitations in spontaneously breathing patients, where driving pressure may underestimate transpulmonary pressure, and in obese patients or those with high intra-abdominal pressures, where driving pressure may overestimate transpulmonary pressure. In addition, previous trials have targeted $\mathrm{V}_{\mathrm{T}}$ and plateau pressures but not driving pressure; therefore, new trials are needed to determine the effect of directly adjusting driving pressure or transpulmonary pressure on clinical outcomes, an approach currently in the process of investigation (ClinicalTrials.gov registrations NCT02365038 and NCT01681225). Finally, targeting ventilation to driving pressure alone is not mindful of the effects of PEEP, which may have an independent effect on lung recruitment and prevention of VILI by preventing atelectrauma. However, despite these caveats to driving pressure, it is difficult to ignore the evidence that setting $\mathrm{V}_{\mathrm{T}}$ levels at $6 \mathrm{~mL} / \mathrm{kg}$ may not provide adequate protection for some of our patients. Driving pressure may be another variable that can provide a safety check for the set $\mathrm{V}_{\mathrm{T}}$, which may be adjusted along with PEEP in order to minimize driving pressure. For example, in a particular patient with ARDS, what should the optimal PEEP and the exact set $\mathrm{V}_{\mathrm{T}}(6,7$, or $8 \mathrm{~mL} / \mathrm{kg})$ be to minimize lung injury? As the trial by Amato et al ${ }^{11}$ demonstrated, if driving pressure is not reduced by reducing $\mathrm{V}_{\mathrm{T}}$ or by increasing PEEP, then there may be no benefit to either adjustment.

As we advance our understanding of the mechanisms of VILI, we must be more rigorous in determining the optimal $\mathrm{V}_{\mathrm{T}}$ setting for each patient rather than applying the same set $\mathrm{V}_{\mathrm{T}}$ to lungs that are mildly, moderately, or severely diseased. Set $V_{T}$ may have to be a fluid value that varies with the degree of aerated lung, and not set at a single value from intubation to extubation. Hence, although we trust that low $\mathrm{V}_{\mathrm{T}}$ ventilation should remain the cornerstone of protective mechanical ventilation today, we should verify that our chosen $\mathrm{V}_{T}$ is achieving the desired physiologic effect and adjust it when necessary.

Maher A Ghamloush MD

Division of Pulmonary, Critical Care, and

Sleep Medicine

Department of Medicine

Tufts Medical Center

Boston, Massachusetts

Erik Garpestad MD

Division of Pulmonary, Critical Care, and

Sleep Medicine

Department of Medicine

Tufts Medical Center

Boston, Massachusetts

\section{REFERENCES}

1. Li G, Malinchoc M, Cartin-Ceba R, Venkata CV, Kor DJ, Peters SG, et al. Eight-year trend of acute respiratory distress syndrome: a population-based study in Olmsted County, Minnesota. Am J Respir Crit Care Med 2011;183(1):59-66.

2. Brun-Buisson C, Minelli C, Bertolini G, Brazzi L, Pimentel J, Lewandowski K, et al. Epidemiology and outcome of acute lung injury in European intensive care units: results from the ALIVE study. Intensive Care Med 2004;30(1):51-61.

3. The Acute Respiratory Distress Syndrome Network. Ventilation with lower tidal volumes as compared with traditional tidal volumes for acute lung injury and the acute respiratory distress syndrome. N Engl J Med 2000;342(18):1301-1308.

4. NHLBI ARDS Network. Studies. http://www.ardsnet.org/studies. shtml. Accessed September 5, 2015.

5. Determann RM, Wolthuis EK, Spronk PE, Kuiper MA, Korevaar JC, Vroom MB, Schultz MJ. Reliability of height and weight estimates in patients acutely admitted to intensive care units. Crit Care Nurse 2007;27(5):48-55.

6. Han S, Martin GS, Maloney JP, Shanholtz C, Barnes KC, Murray S, Sevransky JE. Short women with severe sepsis-related acute lung injury receive lung protective ventilation less frequently: an observational cohort study. Crit Care 2011;15(6):R262.

7. Bojmehrani A, Bergeron-Duchesne M, Bouchard C, Simard S, Bouchard PA, Vanderschuren A, et al. Comparison of usual and alternative methods to measure height in mechanically ventilated patients: potential impact on protective ventilation. Respir Care 2014; 59(7):1025-1033.

8. Jurecki MC, Chatburn RL, Sasidhar M. Accuracy of the electronic health record: patient height. Respir Care 2015;60(12):1715-1719.

9. Terragni PP, Rosboch G, Tealdi A, Corno E, Menaldo E, Davini O, et al. Tidal hyperinflation during low tidal volume ventilation in acute respiratory distress syndrome. Am J Respir Crit Care Med 2007;175(2):160-166.

10. Gattinoni L, Pesenti A. The concept of "baby lung." Intensive Care Med 2005;31(6):776-784.

11. Amato MBP, Meade MO, Slutsky AS, Brochard L, Costa EL, Schoenfeld DA, et al. Driving pressure and survival in the acute respiratory distress syndrome. N Engl J Med 2015;372(8):747-755. 